\title{
Assentamentos informais urbanos e o risco no município de Campinas: Respostas e limites do PAC ${ }^{1}$
}

\section{Informal urban settlements and risk in the city of Campinas: Responses and limits of Growth Acceleration Program (PAC)}

\author{
Silva, Julia Lopes da'; Samora, Patricia Rodrigues2; Macarini, Amanda ${ }^{3}$ \\ 1 Pontifícia Universidade Católica de Campinas, Rua Professor Doutor \\ Euryclides de Jesus Zerbini, 1516 - Parque Rural Fazenda Santa Cândida, \\ Campinas - SP, Brasil, julialopes123@gmail.com \\ 2 Pontifícia Universidade Católica de Campinas, patricia.samora@puc- \\ campinas.edu.br \\ 3 Pontifícia Universidade Católica de Campinas, \\ amanda_macarini@hotmail.com
}

\begin{abstract}
RESUMO
Em função do processo de urbanização desigual que guiou o crescimento de inúmeras cidades brasileiras, grande parcela da população se vê obrigada a habitar áreas ignoradas pelo mercado imobiliário formal, muitas vezes inaptas à ocupação, e que oferecem riscos para as pessoas que ali se instalam. O PAC aparece como resposta governamental ao enfrentamento de tais situações, à medida que provê a infraestrutura necessária, relacionada ao saneamento e à urbanização de favelas, com a finalidade de extinguir os riscos. Diante de tal problemática, destaca-se o caso do município de Campinas, que conta com mais de $1 \%$ de sua população em situação de alto risco. Este trabalho tem como objetivo descrever e analisar três obras do PAC no município: PAC Taubaté, PAC Anhumas e PAC Quilombo, todos relacionados à redução da vulnerabilidade da população local, mas que contam com a remoção e reassentamento de centenas de famílias. Para tanto, nos utilizamos de levantamento em fontes secundárias para produzir uma síntese das iniciativas na redução da vulnerabilidade de tais comunidades e compreender seus resultados. Os resultados foram obtidos em pesquisa de iniciação científica e doutorado, ambas ainda em curso na Pontifícia Universidade Católica de Campinas.
\end{abstract}

Palavras-chave: assentamentos informais urbanos; riscos ambientais; PAC.

\section{ABSTRACT}

Due to the unequal urbanization process that led to the growth of many Brazilian cities, a large part of the population is forced to inhabit areas that are ignored by the real estate market, often unfit for occupation and presenting risks to the people living there. The Growth

\footnotetext{
${ }^{1}$ SILVA, Julia Lopes da; SAMORA, Patricia Rodrigues; MACARINI, Amanda. Assentamentos informais urbanos e o risco no município de Campinas: Respostas e limites do PAC. In: II SIMPÓSIO NACIONAL DE GESTÃO E ENGENHARIA URBANA: SINGEURB, 2019, São Paulo. Anais... Porto Alegre: ANTAC, 2019.
} 
Acceleration Program (PAC) appeared as a governmental response to such situations, as it provided the necessary infrastructure related to sanitation and urbanization of favelas, in order to mitigate risks. The case of Campinas, located in the State of São Paulo, stands out, as more than $1 \%$ of its population is living in high-risk zones. This work aims to describe and analyze three PAC works in Campinas: PAC Taubaté, PAC Anhumas and PAC Quilombo, all related to the reduction of vulnerability of the local population, but at the cost of removing and resettling hundreds of families. Therefore, we use a theoretical and documentary research to verify the effectiveness of these initiatives in reducing the vulnerability of such communities. The results were obtained in research of scientific initiation and doctorate, both still in course in the Pontifical Catholic University of Campinas

Keywords: informal urban settlements; environmental risks; PAC.

\section{INTRODUÇÃO}

O acelerado crescimento populacional, aliado à urbanização desigual das cidades brasileiras, está associado a diversas questões ambientais enfrentadas atualmente, como desmatamento, degradação ambiental e risco. A concentração populacional observada a partir da segunda metade do século XX nos centros industriais brasileiros não contou com ações Estatais que garantissem condições mínimas de infraestrutura e qualidade de vida, resultando em incentivo à ocupação de áreas ignoradas pelo mercado formal e à autoconstrução. Nesse contexto, áreas ambientalmente sensíveis passaram a ser habitadas pelas populações mais pobres que não teriam acesso ao mercado formal de moradia. A população instalada nessas áreas se expõe a riscos ambientais diversos, como inundações e deslizamentos. Ademais, muitas destas áreas são legalmente definidas como Áreas de Preservação Permanente (APP), o que impede ou dificulta a regularização urbanística e fundiária das habitações ali presentes. Como resultado, o Brasil concentra mais de 11,4 milhões de pessoas vivendo em assentamentos informais (IBGE, 2010).

Para combater os riscos que a ocupação destas áreas representa, diversas iniciativas Estatais têm sido desenvolvidas. Dentre elas, destaca-se o Programa de Aceleração do Crescimento (PAC), lançado em 2007, com o objetivo de aumentar os investimentos em infraestrutura para acelerar o desenvolvimento sustentável e superar as desigualdades sociais (ANTONUCCl et al., 2017). Os investimentos do PAC relacionados à redução do risco pertencem às modalidades "urbanização de assentamentos precários" e "saneamento" e são implantados através de intervenções integradas em favelas e da universalização de atendimento. Essas ações do PAC foram efetuadas por parcerias entre o Governo Federal e os governos estaduais ou municipais, sendo estes últimos os que assumem o papel de agentes promotores da intervenção ao realizar obras para provisão de infraestrutura, saneamento, drenagem, implantar equipamentos sociais, produzir moradias, requalificar habitações etc. (NOGUEIRA; PAIVA apud DENALDI et al., 2016)

Campinas, objeto empírico desta pesquisa, foi alvo da implementação de diversas obras do PAC, algumas das quais já concluídas e outras em fase de implementação. No que se refere à prevenção do risco no município, destacam-se o PAC Anhumas, PAC Taubaté e PAC Quilombo, localizados em três bacias hidrográficas distintas. Para a realização dessas obras, houve remoção e reassentamento de centenas de famílias.

O objetivo deste trabalho é conhecer a estratégia pública municipal de enfrentamento do risco - tendo como recorte o contexto do PAC, verificar seus resultados e quais as respostas que o município deu às famílias removidas. O método empregado parte da caracterização do risco em Campinas e das modalidades do PAC aqui implementadas. Foi realizada consulta a materiais disponibilizados pela Companhia de Habitação Popular de Campinas, Caixa Econômica Federal, Prefeitura Municipal de Campinas e Ministério de Planejamento, bem como entrevista não estruturada com funcionária da Cohab Campinas. 


\section{DESENVOLVIMENTO}

Em Campinas, há registro de cerca de 10.000 pessoas vivendo em situação de alto risco, equivalente a $1 \%$ da população municipal (Companhia de Pesquisa e Recursos Minerais, 2013). A situação do risco, na cidade, se relaciona à ocupação generalizada da planície de inundação dos rios municipais, aliada à expansão urbana desordenada de encostas já densamente ocupadas. É neste contexto que se inserem as famílias contempladas pelos PACs Taubaté, Anhumas e Quilombo. A figura abaixo localiza estes empreendimentos no município:

Figura 1 - Localização PACs

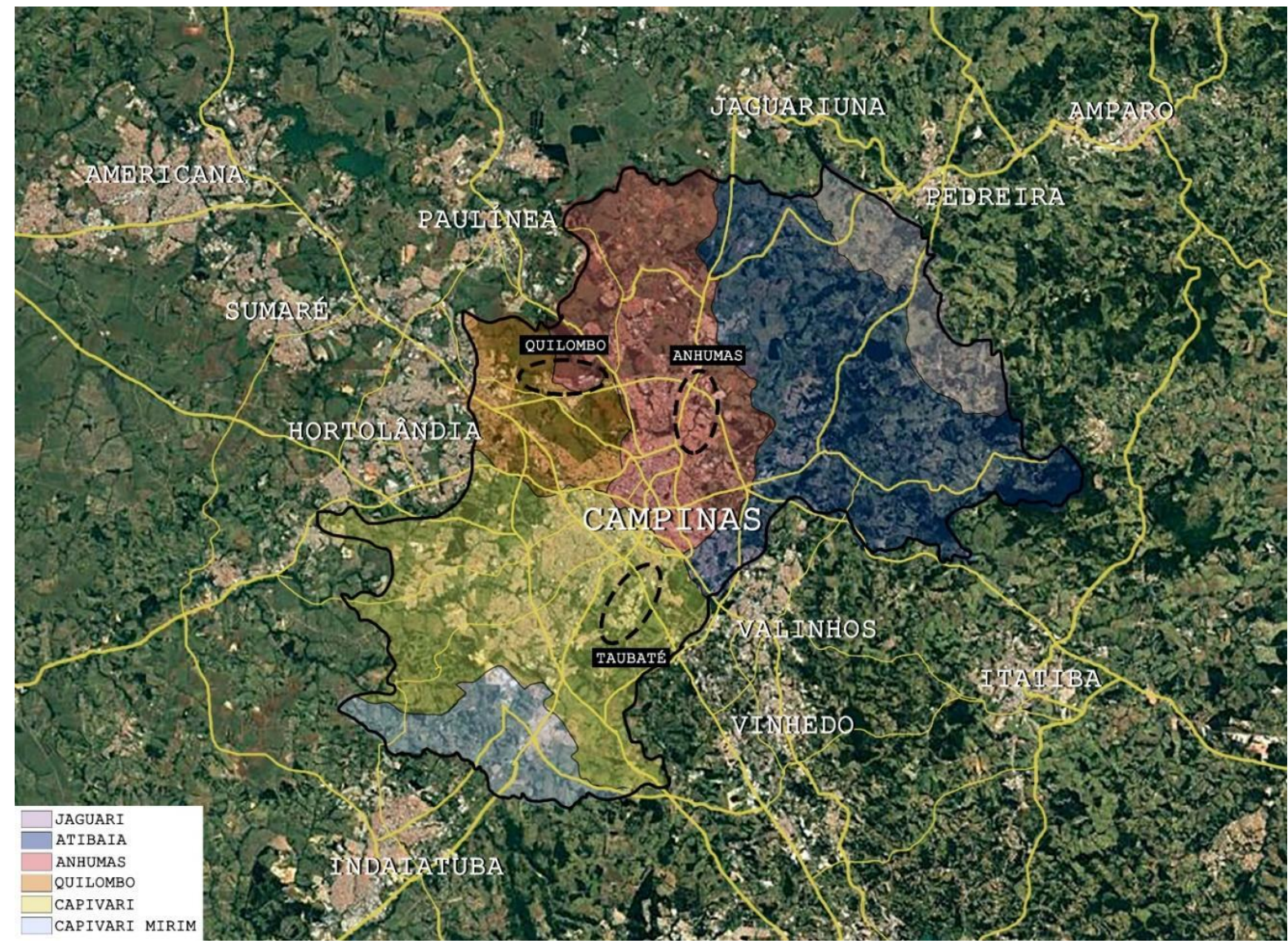

Fonte: As autoras sobre imagem aérea do Google Earth (2019)

\subsection{Os empreendimentos}

O PAC foi um programa que financiou intervenções em assentamentos precários dando liberdade para os municípios implementarem seus projetos, condicionados às diretrizes técnicas. A partir de 2009, a provisão habitacional para famílias removidas integrou o programa Minha Casa Minha Vida (PMCMV), o que teve impacto nas decisões tomadas em cada caso, considerando as regras deste programa habitacional gerido pela Caixa Econômica Federal. Entende-se que proposta de gestão do risco nos casos descritos considerou os recursos federais disponíveis, que levou à adoção de remoção e reassentamento de inúmeras famílias.

PAC Taubaté: Parceria entre o PAC e o PMCMV. Iniciado em 2015, as obras estão suspensas em função dos recursos federais insuficientes, mas têm previsão de retornar no $2^{\circ}$ semestre de 2019. A área de intervenção (figura 2), de $7,5 \mathrm{~km}^{2}$. corresponde aos bairros Santa Rita de Cássia, Jequitibás, Jardim Camboriú, Vila Lourdes-B, São José, Jardim das Bandeiras II-B e Jardim do Lago, na sub-bacia do Córrego Taubaté. As obras envolveram remoção e 
reassentamento de 660 famílias, implantação de Parque Linear nas APPs e regularização fundiária das áreas consolidáveis. Os objetivos foram a manutenção de áreas de preservação ambiental, a prevenção de alagamentos e desmoronamentos, o acesso viário, obras de infraestrutura e saneamento básico etc. (COHAB Campinas, 2016). Para reassentamento das famílias, O MCMV financiou empreendimentos residenciais no loteamento Jardim do Lago, próximos aos locais originalmente ocupados pelos moradores.

Figura 2 - Localização PAC Taubaté

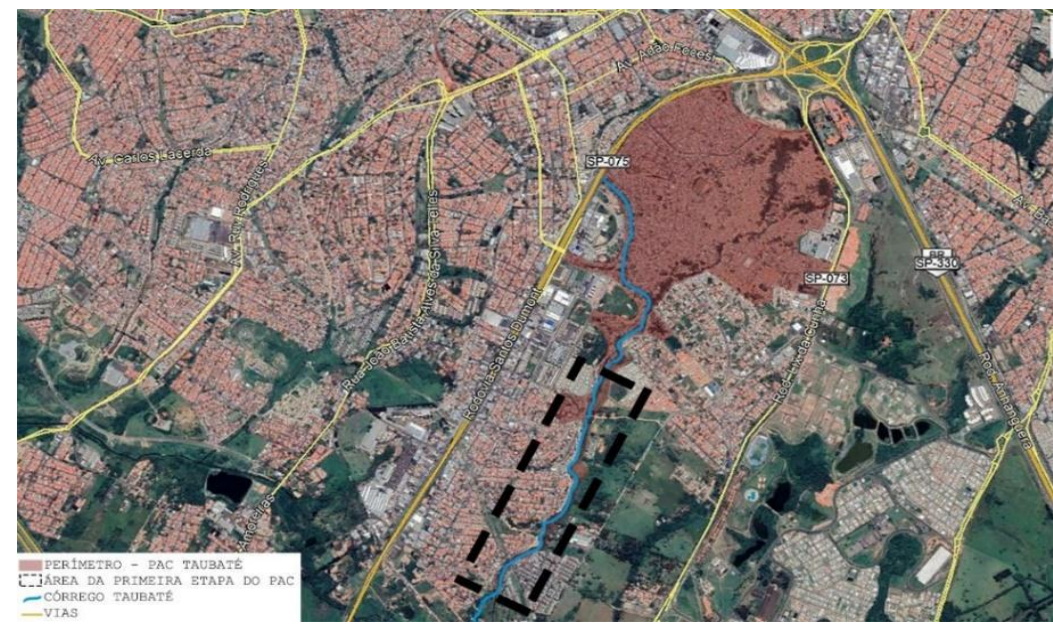

Fonte: As autoras com base no Google Earth (2019)

PAC Anhumas: Projeto de saneamento concluído, cujo local de intervenção (figura 3) se refere aos bairros Núcleo Residencial Gênesis, Guaraçaí, Vila Nogueira e Pq. São Quirino, todos próximos ao Córrego Anhumas, em trecho de aproximadamente $5,2 \mathrm{~km}$. As obras envolveram remoção total das moradias presentes nas áreas de preservação permanente (aproximadamente 400 famílias) e a construção de HIS no perímetro de intervenção do projeto para reassentamento das famílias removidas (Plano Municipal de Habitação, 2011). Nas áreas que foram consolidadas, foram realizadas obras de urbanização, regularização fundiária, implantação de saneamento básico, construção de centros comunitários e recuperação ambiental das APPs - contenção e estabilização de encostas e taludes e desassoreamento do curso d'água (Secretaria Municipal de Habitação, 2011). Não houve canalização do rio. Em entrevista com funcionária da Cohab, salientou-se que houve a preocupação, por parte da população, de áreas de risco próximas ao ribeirão Anhumas.

Figura 3 - Localização PAC Anhumas

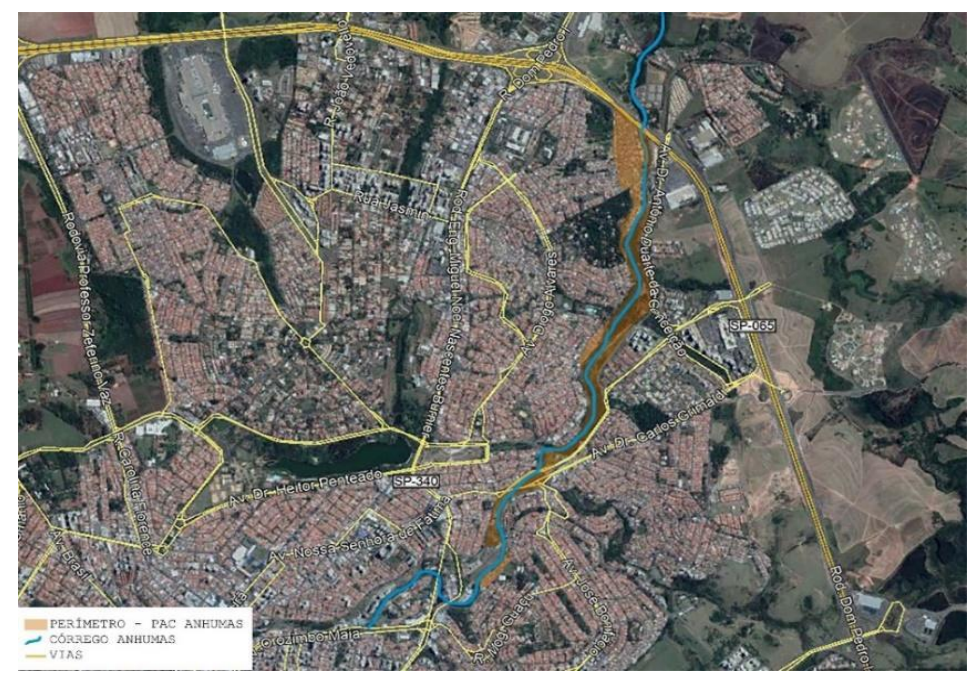

Fonte: As autoras com base no Google Earth (2019) 
PAC Quilombo: Projeto de saneamento, relacionado às obras de macrodrenagem do Córrego da Lagoa e do Ribeirão Quilombo, nos bairros Jd. Santa Monica, São Marcos e Jd. Campineiro (figura 4). O objetivo das obras foi eliminar pontos críticos de inundação da área. Assim como o PAC Taubaté, as obras estão suspensas, com previsão de retorno no $2^{a}$ semestre de 2019. Houve remoção e reassentamento de famílias em áreas sujeitas a inundação, e estavam previstas a construção de bacias de detenção de águas pluviais, barragem, obras de urbanização, regularização fundiária, recuperação ambiental de APPs e construção de HIS para reassentamento das famílias removidas (Secretaria Municipal de Habitação, 2011). Não haverá canalização do córrego, nem construção de parque linear. Para a realização da obra, 705 famílias seriam removidas. O reassentamento, até agora, se deu da seguinte forma: 96 foram para HIS construídas no Bairro San Martin, próximo à área de intervenção das obras; 238 famílias para o Residencial Takanos, também próximo à área de obras; 310 para o Jd. Bassoli, localizado a mais de $15 \mathrm{~km}$ de distância do local das remoções; e 61 famílias ainda não foram reassentadas, ou preferiram receber indenização (Prefeitura Municipal de Campinas, 2013).

Figura 4 - Localização PAC Quilombo

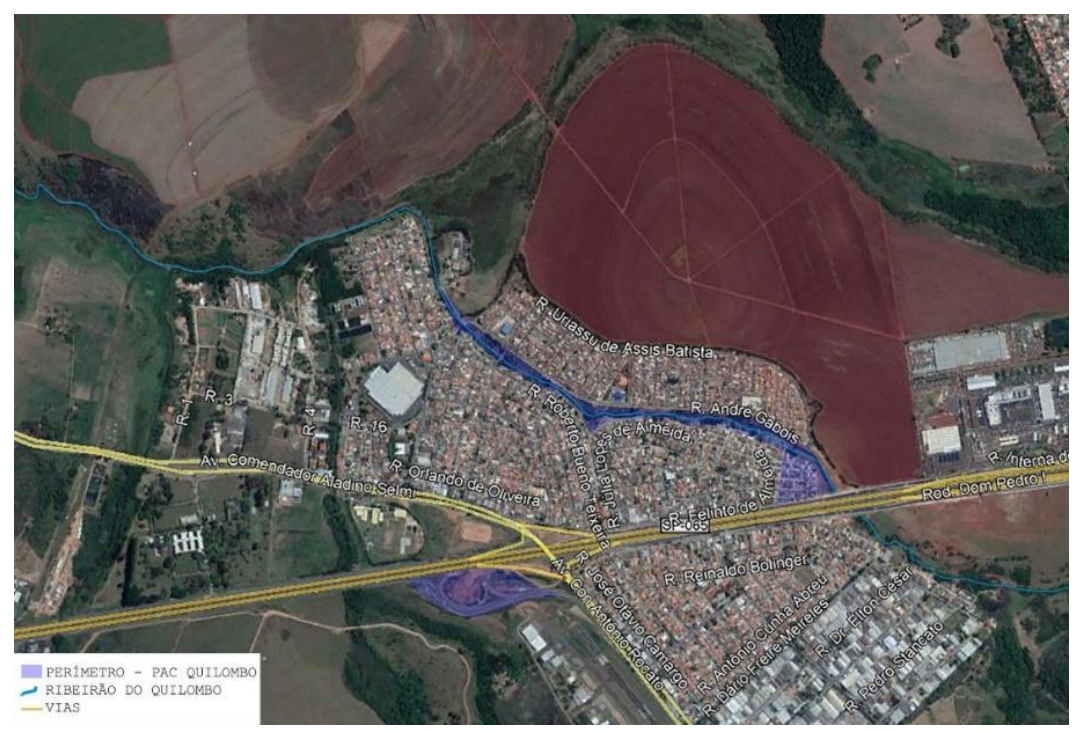

Fonte: As autoras com base no Google Earth (2019)

O quadro abaixo sintetiza as ações realizadas pelos PACs: 
Quadro 1 - Síntese PACs Taubaté, Anhumas e Quilombo

\begin{tabular}{|c|c|c|c|c|c|c|c|}
\hline & Região & Estágio & $\begin{array}{c}\text { Canalização } \\
\text { do córrego }\end{array}$ & $\begin{array}{l}\text { Investi- } \\
\text { mento }\end{array}$ & $\begin{array}{c}\text { Intervenções } \\
\text { realizadas/previstas }\end{array}$ & $\begin{array}{l}\text { Pop. } \\
\text { removida }\end{array}$ & $\begin{array}{c}\text { Local de } \\
\text { reassentamento }\end{array}$ \\
\hline $\begin{array}{l}\text { PAC } \\
\text { Taubaté }\end{array}$ & Sul & Suspenso & Sim & $\begin{array}{l}\mathrm{R} \$ 58 \\
\text { milhões }\end{array}$ & $\begin{array}{l}\text { Acesso viário; } \\
\text { Parque Linear; } \\
\text { Manutenção da APA; } \\
\text { Reassentamento e } \\
\text { construção de HIS; } \\
\text { Regularização } \\
\text { fundiária; } \\
\text { Saneamento. }\end{array}$ & $\begin{array}{c}660 \\
\text { famílias }\end{array}$ & $\begin{array}{l}\text { Integralmente no } \\
\text { perímetro da obra } \\
\text { (Jd. Do Lago) }\end{array}$ \\
\hline $\begin{array}{l}\text { PAC } \\
\text { Anhumas }\end{array}$ & Leste & Concluído & Não & $\begin{array}{l}\mathrm{R} \$ 37 \\
\text { milhões }\end{array}$ & $\begin{array}{l}\text { Infraestrutura; } \\
\text { Reassentamento e } \\
\text { construção de HIS; } \\
\text { Recuperação de } \\
\text { APPs; } \\
\text { Regularização } \\
\text { fundiária; } \\
\text { Saneamento; } \\
\text { Urbanização. }\end{array}$ & $\begin{array}{c}410 \\
\text { familias }\end{array}$ & $\begin{array}{l}\text { Integralmente no } \\
\text { perímetro da obra } \\
\text { (Núcleo Residencial } \\
\text { Guaraçaí e } \\
\text { assentamento Gleba } \\
\text { B) }\end{array}$ \\
\hline $\begin{array}{l}\text { PAC } \\
\text { Quilombo }\end{array}$ & Norte & Suspenso & Não & $\begin{array}{l}\text { R\$ } 58 \\
\text { milhões }\end{array}$ & $\begin{array}{l}\text { Construção de } \\
\text { piscinões; } \\
\text { Reassentamento e } \\
\text { construção de HIS; } \\
\text { Recuperação de } \\
\text { APPs; } \\
\text { Regularização } \\
\text { fundiária; } \\
\text { Urbanização; } \\
\text { Barragem de } \\
\text { contenção. } \\
\end{array}$ & $\begin{array}{c}705 \\
\text { familias }\end{array}$ & $\begin{array}{l}96 \text { UHs: perímetro } \\
\text { das obras (San } \\
\text { Martin) } \\
310 \text { UHs: Jd. Bassoli } \\
238 \text { UHs: Residencial } \\
\text { Takanos } \\
61 \text { ainda sem destino } \\
\text { (ou preferiram } \\
\text { indenização) }\end{array}$ \\
\hline
\end{tabular}

Fonte: As autoras com dados do Ministério do Planejamento, Secretaria Municipal de Habitação e COHAB (2019)

\subsection{Considerações sobre a gestão de risco e sobre as remoções para implantação do PAC}

Observa-se a adoção de medidas estruturais, geotécnicas e hidráulicas, justificadas para redução do risco, como canalização de córregos, implantação de sistema viário e redes de saneamento, recuperação de APPs, barragem de contenção etc. No que diz respeito às soluções habitacionais, nota-se a preferência por remoção da população e realocação das famílias em HIS. Ressalta-se a importância das ações idealizadas e implementadas pelas intervenções aqui descritas para a segurança da população, que estava em situação de vulnerabilidade. A implantação de infraestruturas básicas, ao levar elementos essenciais para a segurança, saúde e qualidade de vida, se mostrou benéfica à população atendida.

As remoções realizadas foram condicionadas à localização em áreas de alto risco de inundação/deslizamento ou por se localizarem em trecho das obras previstas pelo PAC. A preferência por reassentar a população em áreas próximas aos locais de remoção se mostra positiva pois propicia a continuidade de laços e atividades em áreas já habitadas pelos moradores. Contudo, há a exceção do reassentamento de 310 famílias, originalmente na região do Ribeirão Quilombo, para o Jd. Bassoli. Além da distância de 15 $\mathrm{km}$ do local da remoção, ressalta-se que o Jd. Bassoli sofre com a ausência de infraestrutura e serviços urbanos, além de ser seccionado da mancha urbana de Campinas pela rodovia dos Bandeirantes, concretizando um padrão de segregação socioespacial (OKRETIC; BUENO, 2017).

A entrevista permitiu afirmar que a paralisação das obras é um problema, além da incerteza sobre o destino das APPs que foram desocupadas: no caso do córrego Anhumas, alguns trechos foram reocupados. Já no córrego Quilombo, a prefeitura afirma que não 
será implementado parque linear. A canalização dos córregos não foi adotada em dois dos três projetos analisados, conforme informações coletadas na entrevista. Como a pesquisa ainda está em fase de levantamento das informações sobre as obras de risco e macrodrenagem, fica a dúvida se o fato de o canal ter permanecido aberto pode ser interpretado como "não canalizado".

Finalmente, pontuamos a necessidade de reconhecimento da população envolvida como atores sociais ativos no processo de mudanças. Ressalta-se a necessidade de adoção de uma abordagem mais humanista, como lembra Valencio (2014), em que "o ponto de partida das práticas técnicas seria envolver-se com a complexidade social, ao invés de esquecê-la". O empoderamento dos moradores passa pela organização civil dentro da comunidade, de forma a contribuir para a tomada de medidas preventivas. Através da iniciativa popular, a comunidade desempenha papéis ativos nas políticas públicas, e não é tratada como objeto destas (MARCHEZIN, 2015).

\section{CONCLUSÕES}

O processo de urbanização desigual propiciou, em Campinas, a ampla ocupação de áreas consideradas inaptas à ocupação, representando risco para a população que ali se instala. O PAC foi uma oportunidade para que o município efetuasse medidas para redimir as consequências de tal processo. Embora essas ações representem melhorias significativas para as áreas que sofrem intervenções, observa-se a necessidade de uma maior integração do corpo técnico-administrativo com as comunidades contempladas por tais obras, permitindo a emergência de falas, percepções e necessidades dos moradores locais, para que estes deixem de ser vistos como objetos de políticas públicas para assumir papéis ativos na formulação e implementação de respostas aos problemas por eles enfrentados.

Ressalta-se por fim a adoção de grandes obras de engenharia tanto para a canalização e contenção do risco, quanto para as alternativas habitacionais. Como visto em outros trabalhos sobre O PAC, as alternativas de urbanização de favelas de baixo custo não encontraram espaço neste modelo de financiamento de projetos urbanos.

\section{AGRADECIMENTOS}

À CAPES e à PUC-Campinas pelas bolsas de doutorado e iniciação científica que viabilizam o desenvolvimento desta pesquisa.

\section{REFERÊNCIAS}

ANTONUCCI, D. et al. Da luta pela moradia à urbanização de assentamentos precários: a política habitacional no Brasil. In: Zuquim, M.L.; Mazo, L.; Mautner, Y.M.M. (Org.). Barrios populares Medellín: favelas São Paulo. $1^{a}$ ed. São Paulo: FAUUSP, 2017, v. 1, p. 18-32.

COMPANHIA DE HABITAÇÃO POPULAR DE CAMPINAS. Prefeito entrega cronograma de mudanças a famílias do Residencial Vilas de Taubaté. Disponível em <https://www.cohabcp.com.br/noticias/2016/1/pac.html>, acesso em março de 2019.

COMPANHIA DE PESQUISA EM RECURSOS MINERAIS - SERVIÇOS GEOLÓGICOS DO BRASIL. Ação Emergencial para Delimitação de Áreas em Alto e Muito Alto Risco a Enchentes e Movimentos de Massa: Município de Campinas - São Paulo. 18 p., 2013.

DENALDI, R. et al. Urbanização de favelas na Região do ABC no âmbito do Programa de Aceleração do Crescimento-Urbanização de Assentamentos Precários. In: Caderno da Metrópole, v.18, n.35, p.101-118, 2016. 
INSTITUTO BRASILEIRO DE GEOGRAFIA E ESTATÍSTICA - IBGE. Censo demográfico: Aglomerados subnormais, informações territoriais. Rio de Janeiro, 251 p., 2010.

MARCHEZIN, V. The biopolitics of disaster: power, discourses, and practices. In: Human Organization, Vol. 74, No. 4, 2015a.

MINISTÉRIO DO PLANEJAMENTO. Urbanização - Margens do córrego Taubaté. Disponível em <http://www.pac.gov.br/obra/29677>, acesso em março de 2019a.

Saneamento integrado e urbanização de favelas -

ribeirão Anhumas. Disponível em <http://www.pac.gov.br/obra/22636>, acesso em março de 2019b.

Saneamento integrado na bacia do ribeirão Quilombo

Disponível em <http://www.pac.gov.br/obra/24033>, acesso em março de 2019c.

NOGUEIRA, F. R.; PAIVA, C. Uma contribuição ao tratamento de riscos em urbanização de assentamentos precários. In: Óculum ensaios, Campinas, 15(3), p. 437 - 454, 2018.

OKRETIC, G.; BUENO, L. Propostas para processos mais humanizados de remoção e reassentamento. Anais... SEMINÁRIO Interação Universidade e Sociedade: Contribuições para o Plano Diretor de Campinas. Campinas, 2017.

PREFEITURA MUNICIPAL DE CAMPINAS. Habitação entrega chaves de 96 casas com recursos do PAC Quilombo. Disponível em <http://www.campinas.sp.gov.br/noticiasintegra.php?id=21673>, acesso em abril de 2019.

SECRETARIA MUNICIPAL DE HABITAÇÃO. Plano Municipal Habitação de Campinas. Campinas, 2011.

VALENCIO, N. Desastres: tecnicismo e sofrimento social. In: Ciência \& Saúde Coletiva, 19(9), p. 3631-3644, 2014. 